\title{
How to Have (Critical) Method in a Pandemic: Outlining a Culture-Centered Approach to Health Discourse Analysis
}

\author{
Shaunak Sastry ${ }^{*}$ and Ambar Basu ${ }^{2}$ \\ ${ }^{1}$ Department of Communication, University of Cincinnati, Cincinnati, $\mathrm{OH}$, United States, ${ }^{2}$ Department of Communication, \\ University of South Florida, Tampa, FL, United States
}

OPEN ACCESS

Edited by:

Iccha Basnyat,

James Madison University,

United States

Reviewed by:

Satveer Kaur-Gill,

National University of

Singapore, Singapore

Somrita Ganchoudhuri,

Singapore Institute of

Technology, Singapore

*Correspondence:

Shaunak Sastry

sastrysk@ucmail.uc.edu

Specialty section:

This article was submitted to

Health Communication,

a section of the journal

Frontiers in Communication

Received: 22 July 2020

Accepted: 04 September 2020

Published: 14 October 2020

Citation:

Sastry S and Basu A (2020) How to Have (Critical) Method in a Pandemic:

Outlining a Culture-Centered

Approach to Health Discourse Analysis. Front. Commun. 5:585954.

doi: 10.3389/fcomm.2020.585954
In this elucidative essay, we offer a broad outline of the culture-centered approach to health discourse analysis as a warrant for the relevance of critical health communication amid the global COVID-19 pandemic. While there is a proliferation of methods and approaches to health discourse analysis, we outline one broad approach, based on the theoretical tenets and political commitments of CCA. In particular, we emphasize (a) the heuristic value of the CCA's primary and theoretical components - the matrix of culture, structure, and agency, and (b) the importance of exploring discursive erasure as two central principles that guide analysis within this framework. Given the range and scale of existing and likely future transformations in social, political, and cultural understandings of health in the wake of the global COVID-19 pandemic, we offer, through this "how to" essay, a rationale for the continued relevance of critical health communication.

Keywords: culture-centered approach, critical health communication, critical methods, CoVID-19, discourse analysis, health discourses

Discussions around COVID-19 are bound to shape the future of public health and health communication scholarship for the medium to long term. As the "novelty" of the SARS-CoV2 virus causes irreparable human, social, economic, and political impacts across the globe, critical scholars of health have an ethical responsibility to imagine and prepare for the theoretical and practical implications of a post-COVID world. Even as the global pandemic ensues, there is enough evidence to suggest that the terrains on which we form public consensuses around health, privacy, and security are shifting. Critical health scholarship, and in particular, critical health communication (CHC) is well-positioned to outline the already-unfolding transformations in cultural politics, bio-surveillance, immigration policies, militarization, and securitization under the auspices of public health.

\section{COVID-19, POST-NEOLIBERALISM, AND THE FUTURE OF CRITICAL HEALTH COMMUNICATION}

The COVID-19 pandemic, riding on the well-worn trails of global capitalist flows, has, in a matter of months, traveled from a seafood market in Wuhan, China, to more than 210 countries in the world, with a global caseload of more than nine million and counting (as of this writing). While the deep furrows of neoliberal capitalist globalization have undoubtedly accelerated the global spread of the virus, the arrival of the pandemic coincides with the recognition that the neoliberal consensus that has dominated global politics-and thereby global health politics-over the last few decades is giving way to a new political moment. The resurgence of right-wing ideologies 
across liberal democracies in Europe, Asia, and North America, together with the emergence of an expansionist China as a significant engine of global health politics point to the possibilities that the distinctly neoliberal flavor of global health-nudge economics, privatization of healthcare delivery, the creation of individual health "entrepreneurs" through the charity-based interventions of large private foundations-will give way to new modalities of biopower. Indeed, one needs only look at the public health responses to COVID-19 by governments around the world to see suggestions of the authoritarian turn in global health. Many governments have used the exceptions caused by COVID-19 to push through draconian labor laws, violations of privacy, bio-surveillance, and border closures. More fundamentally, public health responses to COVID-19 have recast decades-old tensions between individual "liberties" and the "common good." Organizations such as Humans Right Watch (Roth, 2020), among others have pointed to specific examples in Thailand, Cambodia, Turkey, Egypt, where ruling governments have chosen to downplay the threat of the virus and censured journalists and/or healthcare activists who have critiqued the government's stance. The U.S. government, like its counterpart in Brazil, has gone to great lengths and a concerted effort to deem the pandemic a "hoax," before the sharp uptick in caseload has led these administrations to change course. U.S. President Donald Trump has even gone on to boast about his closing borders as signals of political muscle-flexing; not to forget the June 2020 government diktat to ban the issuance of work visas, the nowaborted attempt to deport international students taking online classes, and the threats to limit the scope of federal funding for a host of efforts associated with the pandemic, including, but not limited to funding for COVID testing.

Why is this relevant to critical health discourse analysis? It's because we have seen this before. The lessons from the decades of HIV/AIDS politicization should tell us something. Just as governments around the world fine-tuned neoliberal ideologies of public health in the wake of the HIV/AIDS pandemic, COVID-19 is likely to be the template for these new set of transformations. The use of "emerging" or "novel" infections as a pretext for making exceptions-to social safety nets, to preventative healthcare access, testing facilities, labor rights, or to universal healthcare-is an old trope in global public health governance (King, 2002; Leach et al., 2010; Sastry and Dutta, 2013). As Priscilla Wald reminds us, the "outbreak narrative" has a particular political-economical function in creating states of disease exceptionalism (Benton, 2015). In this essay, we offer one approach to thinking about the politics of public health in the post-COVID landscape.

Our title references Paula Treichler's influential essay, "How to have theory in an epidemic: cultural chronicles of AIDS," where she offers a heuristic binary (of the "dual epidemics" of biomedicine and signification) to interpret the maelstrom of meanings that circulate during epidemics. Our goal for this essay is to offer a broad template for the critical scrutiny of health discourses, and what such a method would look like in a post-COVID world. We offer some perspectives on "doing" critical analysis of global health discourses, by looking back-on our respective bodies of work in the area-and looking forward to how COVID-19 will shape critical health communication. Before we elaborate on this dual gesture, though, first, an initial attempt to grasp the notoriously slippery question of what we mean by "discourse," or in this case, our specific term, "global health discourses."

Both our research trajectories have been profoundly shaped by the culture-centered approach (CCA) to health communication, a theoretical turn in the field that has prioritized listening to struggles for health within global margins rather than persuading the marginalized to change their behaviors; local, contextual meanings of health over universal "best practices"; knowledge co-created with marginalized groups around the world over theories tested on student samples at the proverbial "large public university"; and reflexive vulnerability over dispassionate scientism as a core research imperative.

Through our engagement with CCA, we have come across instances where a co-participant or a community member discusses issues of health (or safety, or hunger), through a reference to broad social processes that are elusive to pinpoint in ethnographic work. These broad, intangible processes seem immutably linked to the very fabric of society for the individuals and communities that bear their brunt. Farmer (1996) refers to these elusive processes as structural violence-when the very nature of social and political organization in society violates one's ability to survive, thrive or act meaningfully. Structural violence appears in ethnographic interactions as a palimpsest, or an undefined contour, there, but impossible to isolate because of its fundamental relationship to basic social realities in the world. Here's an example to elucidate: in our fieldwork one of us asked Krishan, a migrant truck driver in India why they thought long-distance truck drivers are particularly vulnerable to HIV/AIDS. In response, Krishan alluded to the rush for bauxite mining in their village in the northern Indian state of Uttar Pradesh, which in turn has significantly hurt the prospects of land ownership or tenancy, making traditional agricultural practices unviable, and which in turn "pushed" them out into trucking in order to provide for their family. This involved migrating to the city, leaving home, being away from their spouse/regular sexual partner, and thus, within their lifeworld, into the domain of HIV risk. Here, the "precarity chains" (Silvey and Parreñas, 2020) are visible in encounter, but not explicit enough for analysis.

In a similar example, Rimi, a transgender woman in Omaha, Nebraska in the U.S., who is engaged in sex work, points to how adequate and empathic access to mental health services, and not concerns related to HIV and AIDS, is a critical determinant of health and safety for her, her friends, and colleagues-here again, the connections between mental health, health equity and dignity offer a way to think about HIV/AIDS risk that is not available with functionalist analysis of risk behavior. In another instance, Royston, a Barbadian immigrant living in the Midwestern United States may reflect on his attempts to "pass as straight" while seeking to immigrate into the country, for fear of the stigma of HIV. In each of these instances, taken from our work, rich and layered as they are within complex narratives of health, it becomes apparent that there 
were larger institutional arrangements-often elusive in that they represent the very fabric of societal processes-that directly impinged on their health, even though they may not refer singularly to these arrangements (policies, stigmas, laws, etc.) in particular.

To get to these broad institutional mechanisms, we turned our gaze to potential sites where these arrangements may be more visible. In the first example, the migrant trucker's experiences are a distillation of the increasing forays of global mining conglomerates into mineral-rich rural indigenous communities in India, which are in themselves a result of specific policies crafted into India's developmentalist agenda of resource extraction. For Rimi and her colleagues in sex work, structural violence manifests in a cycle-the myriad levels of social, cultural, medical, discursive discrimination for being a transgender first, and then for being engaged in sex work-leading to and due to lack of employment and insurance, lack of social, medical, and institutional supportleading to sex work and mental health issues - in turn feeding into the multiplying layers of stigma and discrimination and violence. Similarly, the last example harkens back to specific policy language that prevented $\mathrm{HIV}+$ individuals from immigrating to the United States (before the passing of the PEPFAR Act in 2003). For Royston, "passing as straight" was necessary to reduce the chances of being asked to produce secondary HIV testing documentation through the immigration process.

When we refer to global health discourses, we mean these broad connections between individual, culturallyrooted experiences of health and how these experiences are materially and symbolically linked to health articulations within broad institutional frameworks (policies, laws, ideologies, cultural productions, media, etc.) Discourse here refers to an entire complex of articulations around health-the sites of articulation, the historical patterning of the articulation, as well as the specific articulation itself. We use the term in concordance with (Reisigl and Wodak, 2015) who characterize discourse as "a cluster of context-dependent semiotic practices that are situated within specific fields of social action" that is socially constituted and socially constitutive" (Reisigl and Wodak, 2015, p. 89) and "related to a macro-topic" (Reisigl and Wodak, 2015, p. 89).

This is admittedly a broad brush to paint with-our work has investigated the ideological underpinnings of such discourses across a diverse genre of texts-from policy articulations like the U.S. President's Emergency Plan for AIDS Relief (PEPFAR) (Sastry and Dutta, 2012, 2013), print news-on the 2014 Ebola epidemic in West Africa (Sastry and Dutta, 2017), and the HIV/AIDS epidemic in India (Sastry and Dutta, 2012), documentary films like "Born into Brothels" (Mendes et al., 2010), the social media content of health institutions (Sastry and Lovari, 2017) and others. While these projects have largely been undertaken independently, or with other authors, we recognized over time that we were converging on a particular mode of reading of healthrelated texts.
The point is to make the case for a heterodox CCA methodology [any process that leads to the "identification of objects of research" (Fairclough, 2013, p. 234)]. We demonstrate that the heuristic value of the CCA lies in conceptualizing objects of research that can be analyzed through different methods. We are not as invested in introducing (another) general "method" of discourse analysis of health, as we are in showing how CCA animates one way of doing analysis in critical health communication. We see heuristic value in this method and recognize its potential to broaden the set of tools at hand for critical health scholars.

The essay follows thus: we begin with a brief introduction of CCA and its primary and secondary components. We then offer direct and practical ways in which we harness CCA concepts in the service of textual analysis of health discourses. Along the way, we take brief detours to situate this method within existing literature-like critical discourse analysis (Fairclough, 2013), modes of analysis-like the Peircean idea of "abduction" (Timmermans and Tavory, 2012) ${ }^{1}$, and debates about ethics in critical analysis-e.g., the role of self-reflexivity vis-à-vis fidelity of interpretations (de Souza, 2019) ${ }^{2}$ We offer some examples of this method from within our work, before ending with a discussion on limitations and potential contributions of this kind of scholarship.

\section{CULTURE-CENTERED APPROACH TO HEALTH COMMUNICATION}

The culture-centered approach to health communication, as represented by the writings of (Airhihenbuwa, 1995; DuttaBergman, 2005; Dutta, 2008; Basu and Dutta, 2009; Sastry et al., 2019), theorizes linkages between culture, health, and marginalization. Originating with the critique of the Eurocentric (e.g., Basu, 2011), individual behavior-change focused (Dutta, 2007), and status-quo (Sastry and Dutta, 2011) traditions of health communication theorizing, the CCA has developed a robust theoretical framework dedicated to a social-change focused vision for health communication theorizing that is developed in co-construction with marginalized communities across the globe (Dutta, 2008).

At its crux, the CCA is invested in how subaltern narratives of health reveal the complex interplay between culture, structure, and agency. Culture refers to the gamut of local, dynamic, meaning-making practices around health, while Structure refers to the socio-politico-institutional framework or environment within which health is accessed (or denied) for individuals and communities at the margins. Agency, an intrinsic human quality, linked to ability, drives human action and purpose

\footnotetext{
${ }^{1}$ While we do not have the space to develop it here in full, scholars interested in textual analysis of health in general, and CCA in particular will find (like we did), the large body of literature on critical discourse analysis and abduction relevant. See Fairclough (2013), Reisigl and Wodak (2015), Timmermans and Tavory (2012), and Tracy (2013).

${ }^{2}$ In this collection of articles itself, Rebecca de Souza offers an excellent analysis of broad ethical concerns in doing critical health work. See de Souza (2019).
} 
(such as the quest for health, safety, well-being, food security, etc.) Human agency emerges in response to the characteristics of one's structural environment, and structures themselves respond to human agents. Work in the CCA tradition highlights this constant interplay-or dialectic-between structure and agency in the context of marginalized communities' struggles for health (Sastry et al., 2019). For instance, the nature of structural configurations (trade policies, land ownership patterns, generational poverty, development projects) can affect the livelihoods, safety, well-being and economic prospects of marginalized communities, whose actions to counter and negotiate these structures (migration, high-risk work, contingent employment, leaning on social/cultural others) reveal agency in the face of such structural constraints (Zoller and Sastry, 2016). Culture, defined as local meaning-making practices, offers a vantage point to understand this dialectical relationship between structure and agency. The political impetus of the CCA-as a primarily ethnographic approach to theory-building-is to co-construct solutions to health problems with communities through identifying the interactions of culture, structures, and agency in local contexts.

As one of us has recently argued, the culture-structureagency tripartite represents a fundamental ontological premise of the CCA (Sastry et al., 2019), ontology being the branch of metatheory concerned with problem definition. As a theory of (health) communication, CCA looks at the dynamic interactions between culture, structure, and agency as the very site of meaning-making around health. This tripartite conceptualization represents the "under the hood" of the CCA: it is a sensitizing mechanism within this form of inquiry, guiding research questions, study design, data collection, and analysis. Articulating health within this matrix allows for questions about what (and whose) articulations of health circulate, and what meanings of health are hidden/missing/erased. This is evident from our respective ethnographic work in the CCA tradition, (e.g., Basu and Dutta, 2009; Basu, 2011; Basu et al., 2016; Sastry, 2016a,b; Sastry et al., 2017). By referring to the culture-structureagency conceptualization as a sensitizing mechanism, we are recognizing it as an intellectual habitus, or a preferred mode of organizing inquiry that bleeds into our analysis of health discourses in general. This sensitizing framework allows us to ask the critical question: "What voice is missing here?" In other words, we have recognized that the CCA directly shapes "our way" of looking at texts through these two gestures: (a) using the culture-structure-agency matrix as a sensitizing framework, and (b) asking "what is missing from this articulation?" We address each one in turn.

\section{THE CULTURE-STRUCTURE-AGENCY MATRIX AS A SENSITIZING FRAMEWORK}

So, what does it mean, in a practical sense, to use the culture-structure-agency conceptualization as a guide to analysis of discourse? In essence, it means using the terms as a broad guideline for preliminary categorization/organization of textual data. Put another way, using this framework allows us to look at the interdiscursive connections within a text or a series of texts. Interdiscursivity refers to how discourses within a specific domain of social action relate to, borrow from, or depend on others, from different domains (Reisigl and Wodak, 2015). The C-S-A matrix is a heuristic if often inexact and approximate framework to disassemble and distinguish the discursive claims made in a text, and evaluate the claims against each other. This framework allows us to examine how the meanings of health operating within a specific discursive domain depend on, borrow, colonize (or are in themselves colonization of) discursive claims from other domains.

Within the CCA, culture refers to local meaning-making practices around health. When used as a heuristic, we organize all textual articulations about rituals, practices, behaviors, gender norms, barriers, stereotypes, challenges, and so on within the broad umbrella of culture. An alternate approach is to code within the culture bucket all Meso-level references to health.

Here we are very cognizant (and intentional) in deviating from the orthodox operationalization of culture in the CCA-local, micro, dynamic - and acknowledge the years of painstaking work it has taken to establish (and defend) the precept that people who belong to a culture get to define and name it. Our goal here, however, is analytical, not prescriptive. Our raw, and imprecise categorization is a deliberate strategy against the crystallization of data into an otherwise well-defined concept in the theory, to be open to new, contradictory, and therefore interesting ways in which the data can present itself.

In the same vein, we would use the term structure to identify instances of the institutional domain of health. Articulations of policy, trade, population-level data, macrotrends and observations, references to rules, laws, global flows, global governance, etc. are coded under this bucket. Another way of saying it is that all references to the broadest, most macro conceptualizations of health are coded into "structure."

Finally, we take the term agency to refer to articulations at the micro or individual level of analysis. All references to individual behaviors, health-seeking, testimonials, first-person narratives, patient non-compliance, individual differences, individual achievements, success stories, are all coded within this bucket. At this stage, we momentarily suspend the political and deliberate valence of how culture, structure, and agency are coded within the CCA-we are not presuming for the moment that all action is "agentic," just as not all behavior is "cultural," and not all violence is "structural."

The matrix provides a viable sensitizing framework to organize and categorize data, in a process akin to "first level coding" (Tracy, 2013) or "open coding" (Corbin and Strauss, 2008) in a qualitative research sense. In other words, we do not categorize the data within a culture-structure-agency matrix for it to neatly fit within our "favorite theory," to use Michael Burawoy's phrase (Timmermans and Tavory, 2012, p. 169). Rather, this categorization prepares the ground for us to be unprepared by what the data will reveal. To put it yet another way, we do not seek confirmation of the 
theoretical tenets of CCA through the data in a deductive sense; instead, we use the CCA categorization to find out what is genuinely new, interesting, or contradictory in the data. We think of the CCA as a preferred mode of thinking about health, or an intellectual habitus of familiarity, so that using it to document all that is familiar is a first step toward engaging "imaginative thinking about intriguing findings and then return(ing to the data) to check our conjectures" (Charmaz, 2014, p. 137-138).

Readers will observe that this movement-from data to theory and back-resembles "abductive reasoning" in qualitative research terms or the "inferential creative process of producing new hypotheses and theories based on surprising research evidence." (Timmermans and Tavory, 2012). Abductive reasoning, according to the pragmatic philosopher Charles Sanders Peirce, uses a logic that is different from deduction or induction, and in Pierce's account, precedes them in the logico-scientific process of theory construction. While scholars differ in the primacy they accord to abductive reasoning within textual and/or qualitative analysis, our approach is consistent with that of Timmermans and Tavory (2012), who call for "centering abduction" in analysis. Here's an example from one of our earlier pieces that elaborates this.

In Sastry and Lovari (2017), we write about the Centers for Disease Control's "Disease Detectives" and how the "local cultural expertise" of these public health experts was framed as an exemplar of the CDC-and by synecdoche, the United States' leadership in Ebola prevention. How "local cultural" expertise is defined here is categorically different from how it is conceptualized within the CCA-and yet, coding this data within the "culture" framework allows us to think about the difference meaningfully, ask questions about how this cultural expertise is constructed, and the evidentiary basis for cultural expertise. In this particular case, the fact that disease detectives are invariably American "elite public health sleuths" (Sastry and Lovari, 2017, p. 334) who know the importance of respecting "African culture" (p. 334) opens up the door to asking the important question of missing voices and questioning absences in the discursive space.

\section{Whose Voice Is Missing Here? Voice, Erasure, and the Politics of Representation}

As is immediately apparent from the above example, the critique of the "disease detective" discourse hinges on a critical reading of this cultural articulation. Put another way, the critique offers an alternate conceptualization of disease expertise that considers local policymakers, community health workers, health providers, etc., whose work was shown to be crucial in managing the Ebola crises in 2014. Here, this argument was established through the analytical gesture of asking the "Whose voice is missing here?" question. Another example of this is how global HIV prevention interventions targeting commercial sex workers almost always, and universally, advocate the use of condoms and regular blood tests ignoring local cultural perspectives on how health is made sense of and negotiated, leave alone questions on whether HIV is indeed an issue of concern, and if so, what local problemsolutions emerge. These absences in the examples above highlight the concept of "discursive erasure."

\section{Discursive Erasure}

As a theory of health communication, one of the primary contributions of CCA has been the emphasis on uncovering "discursive erasure" from the domains of knowledge creation about health. What counts as knowledge, and who gets to create it? Discursive erasure refers to the process of being "written out" of spaces of knowledge creation. Who gets to claim expertise over the other, and based on such expertise, gets to fix the other in the discourse, through knowledge claims about cultures, practices, or beliefs? This emphasis on erasure emerges from CCA's theoretical rooting in Subaltern Studies, which concerned itself with the politics of historiography - the writing of historyand how the histories of the subaltern, or the most marginalized sections of society, are written in ways that erase their agency. CCA takes this impetus and applies it to how knowledge claims are made about subaltern groups across the globe, and how the health agendas of such groups are rendered invisible, or irrelevant when compared to the health agendas forwarded by “experts” outside such communities. For example, Basu's (2010) work argues that health interventions targeting sex workers in India need to recognize that sex workers see themselves primarily as mothers providing for their children, and not as a "high-risk" group for HIV/AIDS, as they are often construed within health discourses. The material risks that sex workers undertake are constellated within their role as mothers who provide sustenance and care $-\mathrm{a}$ fact that is often erased from the discourse on sex workers.

As a pragmatic step guiding the analysis of health discourses, the "What is missing" question is akin to what Stuart Hall calls an "oppositional reading" of texts-a reading that is based on a suspicion of the fundamental codes within the text. By asking "what is missing," we orient ourselves toward the ideological consensuses that function within the text and seek out alternative ideological possibilities. Having coded texts based on the culture-structure-agency matrix, we now probe about silences, omissions, and erasures. This is, of course, a deeply political act that harbors no pretenses about neutrality on the part of the analyst. Such motivated hermeneutics seeks gaps, omissions, foreclosures from the text in a deliberate, personal sense.

This particular gesture often troubles our colleagues, students, and reviewers. The idea that we ask "what is missing from the discourse?" does not categorically assume that we (or you!) know. This doesn't assume an omniscient analyst, but it does presume that the analyst brings their enacted, embodied, and reflexive lifeworld into considering what is missing. And in this sense, the subjectivity of the analyst does matter. For instance, one of us was recently working with a graduate student on their Masters' thesis project on arsenic poisoning in groundwater in West Bengal, India. Having completed their fieldwork, the student was remarking on the fact that the data they collected was populated exclusively by narratives of male participants and that they did not have any "empirical" 
data about how rural women felt about arsenic poisoning of village groundwater. As an aside, arsenic poisoning is a geogenic feature of the Gangetic basin, and is occurs naturally in large parts of South-East Asia that are dependent on groundwater. Groundwater wells that are found to be arsenic-laced are often sealed off, meaning that local community members have to rely on alternate sources to collect water for daily use. Often, this means traveling to neighboring villages, or the nearest "clean" groundwater well.

Even though we knew-from cultural context and secondhand experience-that the gendered burden of drawing water falls largely on women within this cultural context and that the burden of sealing off local water wells would change women's lives in different ways than it did the men who shared their stories with us, this argument was looked at very unfavorably by colleagues, thesis committee members, and reviewers since it was not based on "empirical" data. How could we claim that arsenic poisoning exacerbated gender inequities even if we had not "actually heard" women attest to these patterns? Here, the rigid insistence of empiricism in the face of a rather moderate claim-that women's lives are more burdened by arsenic remediation interventions-speak to the precise dilemma at hand. Discursive erasure here occurs not just at the level of participation-the failure to record women's narratives, but at the misplaced empiricist demand for positivist claims by peer reviewers, ostensibly those not from the same cultural context. To analyze on the lines of "what is missing" depends, partially, at least, on the embodied experience of the analyst. In this case, this embodiment is not just the fact that the student shares a common cultural, linguistic, and ethnic context with the participants (even though they diverge in terms of class and socio-economic privileges), but also the fact that our analysis is shaped by our access to decades of ecofeminist literature that attests to the inequities inherent to water collection in India and the global South. Analyst positionality opens up avenues for tracing discursive erasure.

A disclaimer: we are arguing for researcher positionality as a fundamental tool in analysis, but we are not suggesting that ouror any-positionality is transcendent. Speaking for the subaltern, or being rendered the "native informant" carries with it the infinite regress of the politics of representation-who can truly speak for the subaltern. Our positionality as particular subjects within a discursive arena is limited: in the thesis example, we don't claim to speak for the women in the villages where the fieldwork was conducted, and we don't claim to have an authentic voice to represent them because we look like, talk like, or claim to think like them. And yet, what we do know about the context from our own lived experiences is not circumstantial, in this case, and is central to the analysis. Analysis in the CCA is based on being reflexive about how the very process of critique of discursive erasure can itself create avenues for further erasure. Just as researcher "common sense" is predicated as a given in constructing research instruments like surveys, or experimental protocols, analysis within the CCA requires attending to the "common sense" that derives from the embodied, reflexive self of the analyst.

\section{CRITICAL HEALTH COMMUNICATION, GLOBAL HEALTH, AND POST-COVID FUTURES}

Epidemics are characterized by semiotic excess: they create pathways through which meaning-making processes are transformed and/or accelerated. Critical health communication scholars, invested in exploring how issues of power, control, ideology, and identity shape meaning-making practices in health, look to epidemics as sites of both transformation and reification of existing understandings of health. The COVID-19 pandemic has already led to fundamental transformations, and will continue to foment further transformations in how we understand health. These transformations play out at the "micro" discursive level, for instance, in how the language around health changes. Consider how discursive terms referring to masks, "social distancing," "droplets vs. aerosols," and "flattening the curve" enter the public lexicon and are imbued with political meaning. The rate and scale of Meso-level and macro-level transformations in understandings of individual and public health are staggering. At the level of discourse, this essay outlines a broad methodological framework to analyze the communicative claims that undergird such transformations within a text, a genre of texts, or a bounded topical area.

The point of this essay, as we have said previously, is not necessarily to unveil a "new" approach to analyzing health discourses, but rather to outline one (our) way of apprehending and critiquing the political bases of the claims made within such discourses. This explicit political claim lies at the heart of critical health communication (Lupton, 1994; Zoller and Kline, 2008) which looks at the struggle for health as a fundamental starting point. Whether or not the fallout of the global pandemic has rendered our existing political imaginaries redundant is up for debate (It has certainly led to a renaissance of the long-form journalistic essay that deconstructs the cultural politics of the disease. A plethora of them have emerged in the wake, opening up new avenues for the age-old question of "where (critical) health communication may be found" McKnight, 1988). Consider this meme circulating on Chinese social media in January 2020, in the early days of the epidemic, as news emerged of COVIDcases rising in Lombardy, Italy, and as Italian officials made statements about mandatory lockdown measures and mask use as antithetical to civil liberties: "With quarantine/no human rights //Without quarantine/no humans left." The linguistic quip is undergirded by the recognition that the response to COVID-19 has led to new reckonings, on both the left and right, around issues of globalization, immigration, and surveillance.

Tectonic shifts in public health governance notwithstanding, the continued relevance of critical health communication, and by extension, of the need to critically examine the fundamental assumptions underlying healthcare arrangements is nowhere more apparent than in the abject failures of the United States' response to COVID-19. A growing medical consensus points to the systemic flaws of the private healthcare model espoused in the US, in particular the monopoly capitalist formations that make up critical elements of the US healthcare system 
that have led to the disproportionately skewed burden of COVID-19 morbidity and mortality in the United States. In comparison, economies with robust public health delivery systems, and in particular those built on socialist premises of public funding and equity in healthcare access have tended to have the best COVID-19 outcomes. The lessons from New Zealand, Vietnam and the Indian state of Kerala (the latter a dramatic exception from the rest of the Indian COVID19 response) make this amply clear (Dutta et al., 2020). The political economy of healthcare systems has never been more relevant, and critical health communication affords a pathway to interrogate how the health claims undergirding such systems are discursively constructed.

In this essay, we offered a broad outline for interrogating the cultural and social politics of meaning-making in public health, based on our background in the culture-centered approach to health communication. We outline how the

\section{REFERENCES}

Airhihenbuwa, C. O. (1995). Health and culture: Beyond the Western paradigm. Sage.

Basu, A. (2010). Communicating health as an impossibility: sex work, HIV/AIDS, and the dance of hope and hopelessness. South. Commun. J. 75, 413-432. doi: 10.1080/1041794x.2010.504452

Basu, A. (2011). HIV/AIDS and subaltern autonomous rationality: a call to recenter health communication in marginalized sex worker spaces. Commun. Monogr. 78, 391-408. doi: 10.1080/03637751.2011.589457

Basu, A., Dillon, P. J., and Romero-Daza, N. (2016). Understanding culture and its influence on HIV/AIDS-related communication among minority men who have sex with men. Health Commun. 31, 1367-1374. doi: 10.1080/10410236.2015.1072884

Basu, A., and Dutta, M. J. (2009). Sex workers and HIV/AIDS: analyzing participatory culture-centered health communication strategies. Hum. Commun. Res. 35, 86-114. doi: 10.1111/j.1468-2958.2008.01339.x

Benton, A. (2015). HIV exceptionalism: development through disease in Sierra Leone. University of Minnesota Press. doi: 10.5749/minnesota/9780816692422.001.0001

Charmaz, K. (2014). Constructing grounded theory, 2nd edn. Sage. doi: 10.1002/9781405165518.wbeosg070.pub2

Corbin, J. M., and Strauss, A. L. (2008). Basics of qualitative research: techniques and procedures for developing grounded theory, $3 r d$ edn. Sage Publications, Inc. doi: 10.4135/9781452230153

de Souza, R. (2019). Working the hyphen from below: the "thick decryption of subtext" and the micro-politics of knowledge production. Front. Commun. 4:68. doi: $10.3389 /$ fcomm. 2019.00068

Dutta, M. J. (2007). Communicating about culture and health: theorizing culturecentered and cultural-sensitivity approaches. Commun. Theory 17, 304-328. doi: 10.1111/j.1468-2885.2007.00297.x

Dutta, M. J. (2008). Communicating Health: A culture-centered approach. Polity.

Dutta, M. J., Elers, C., and Jayan, P. (2020). Culture-centered processes of community organizing in COVID-19 response: notes from Kerala and Aotearoa New Zealand. Front. Commun. 5:62. doi: 10.3389/fcomm.2020.00062

Dutta-Bergman, M. J. (2005). Theory and practice in health communication campaigns: a critical interrogation. Health Commun. 18, 103-122. doi: $10.1207 /$ s15327027hc1802_1

Fairclough, N. (2013). Critical discourse analysis: the critical study of language, 2nd edn. Taylor and Francis. doi: 10.4324/9781315834368

Farmer, P. (1996). On suffering and structural violence: a view from below. Daedalus, 125, 261-283.

King, N. B. (2002). Security, disease, commerce: ideologies of postcolonial global health. Soc. Stud. Sci. 32, 763-789. doi: 10.1177/030631270203200507 broad theoretical movements of the CCA have animated our approach to doing textual analysis in health. We hope that scholars will find this approach productive to analyze the many transformations that are undoubtedly at hand. Moreover, we hope to have shown that while the risks and fallouts of this novel virus are indeed that-novel-so much of its politics has been made apparent by epidemics that preceded it. The need of the hour is to look back as much as it is to look ahead.

\section{AUTHOR CONTRIBUTIONS}

The authors jointly conceptualized the article. The article was written collaboratively, with each author adding to existing versions of drafts. The final article was lightly edited for clarity by the first author. All authors contributed to the article and approved the submitted version.
Leach, M., Scoones, I., and Stirling, A. (2010). Governing epidemics in an age of complexity: narratives, politics and pathways to sustainability. Glob. Environ. Change 20, 369-377. doi: 10.1016/j.gloenvcha.2009.11.008

Lupton, D. (1994). Toward the development of critical health communication praxis. Health Commun. 6, 55-67. doi: 10.1207/s15327027hc0601_4

McKnight, J. (1988). Where can health communication be found? J. Appl. Commun. Res. 16. doi: 10.1080/00909888809365270

Mendes, K., Silva, K., Basu, A., Dutta, M. J., Dunn, J., Attwood, F., et al. (2010). Commentary and criticism: representations of sex workers. Fem. Media Stud. 10, 99-116. doi: 10.1080/14680770903457469

Reisigl, M., and Wodak, R. (2015). "The discourse-historical approach," in Methods in Critical Discourse Studies, eds R. Wodak and M. Meyer (Sage). 23-61.

Roth, K. (2020). "How authoritarians are exploiting the COVID-19 crisis to grab power," in The New York Review of Books. Available online at: https:// www.nybooks.com/daily/2020/03/31/how-authoritarians-are-exploiting-thecovid-19-crisis-to-grab-power/ (accessed July 15, 2020).

Sastry, S. (2016a). Long-distance truck drivers and the structural context of health: a culture-centered investigation of Indian truckers' health narratives. Health Commun. 31, 230-241. doi: 10.1080/10410236.2014. 947466

Sastry, S. (2016b). Structure and agency in long-distance truck drivers' lived experiences of condom use for HIV prevention. Cult. Health Sex. 18, 553-566. doi: 10.1080/13691058.2015.1094575

Sastry, S., and Dutta, M. J. (2011). Postcolonial constructions of HIV/AIDS: meaning, culture, and structure. Health Commun. 26, 437-449. doi: $10.1080 / 10410236.2011 .554166$

Sastry, S., and Dutta, M. J. (2012). Public health, global surveillance, and the "emerging disease" worldview: a postcolonial appraisal of PEPFAR. Health Commun. 27, 519-532. doi: 10.1080/10410236.2011.616626

Sastry, S., and Dutta, M. J. (2013). Global health interventions and the "common sense" of neoliberalism: a dialectical analysis of PEPFAR. J. Int. Intercult. Commun. 6, 21-39. doi: 10.1080/17513057.2012.740682

Sastry, S., and Dutta, M. J. (2017). Health communication in the time of Ebola: a culture-centered interrogation. J. Health Commun. 22, 10-14. doi: 10.1080/10810730.2016.1216205

Sastry, S., and Lovari, A. (2017). Communicating the ontological narrative of Ebola: an emerging disease in the time of "Epidemic 2.0." Health Commun. 32, 329-338. doi: 10.1080/10410236.2016.1138380

Sastry, S., Stephenson, M., Dillon, P., and Carter, A. (2019). A meta-theoretical systematic review of the culture-centered approach to health communication: toward a refined, "nested" model. Commun. Theory. doi: 10.1093/ct/qtz024. [Epub ahead of print].

Sastry, S., Zoller, H. M., Walker, T., and Sunderland, S. (2017). From patient navigation to cancer justice: toward a culture-centered, community-owned 
intervention addressing disparities in cancer prevention. Front. Commun. 2:19. doi: 10.3389/fcomm.2017.00019

Silvey, R. and R. Parreñas (2020). Precarity chains: cycles of domestic worker migration from Southeast Asia to the Middle East. J. Ethnic Migr. Stud. 46, 3457-3471. doi: 10.1080/1369183X.2019. 1592398

Timmermans, S., and Tavory, I. (2012). Theory construction in qualitative research: from grounded theory to abductive analysis. Sociol. Theory 30, 167-186. doi: 10.1177/0735275112457914

Tracy, S. J. (2013). Qualitative research methods: collecting evidence, crafting analysis, communicating impact. Wiley-Blackwell.

Zoller, H. M., and Kline, K. N. (2008). Theoretical contributions of interpretive and critical research in health communication. Ann. Int. Commun. Assoc. 32, 89-135. doi: 10.1080/23808985.2008.116 79076
Zoller, H. M., and Sastry, S. (2016). "Communicating the politics of healthcare systems," in Storied Health and Illness: Communicating Personal, Cultural, and Political Complexities, eds J. Yamasaki, P. Geist-Martin, and B. F. Sharf (Waveland Press).

Conflict of Interest: The authors declare that the research was conducted in the absence of any commercial or financial relationships that could be construed as a potential conflict of interest.

Copyright (c) 2020 Sastry and Basu. This is an open-access article distributed under the terms of the Creative Commons Attribution License (CC BY). The use, distribution or reproduction in other forums is permitted, provided the original author(s) and the copyright owner(s) are credited and that the original publication in this journal is cited, in accordance with accepted academic practice. No use, distribution or reproduction is permitted which does not comply with these terms. 